\title{
RANCANG BANGUN INTERNET SERVICE PROVIDER (ISP) LOKAL DENGAN JARINGAN WIRRELESS DAN MIKROTIK OS
}

\author{
Rizal Adi Siswanto, Choirul Anam, Sujono \\ Fakultas Teknologi Informasi Universitas KH.A. Wahab Hasbullah
}

Correspondence Author: rizalandrizal7@gmail.com

\begin{abstract}
ABSTRAK
Wireless LAN network is a community-based network or community network, why so for the cost of monthly expenditure will be much more affordable than the price of the official ISP. This intenet network is commonly referred to as Local ISP because its coverage area is only interdistrict or rural. With the internet it can provide ease of communication process by eliminating the distance and time that has been felt as a factor in particular inhibitors in villages and sub-districts are still rarely affordable telephone cable. Internet network using Wirreless Antenna is expected to provide convenience and comfort of internet access for residents in the Rural. This internet network uses Wirreless antenna as a data transmission medium or internet carrier, and this network uses mikrotik RB 750 where mikrotik here function to manage network traffic.
\end{abstract}

Keywords: Internet, Wireless Antenna, mikrotik RB 750, Local ISP.

\section{INTISARI}

Jaringan wireless LAN adalah jaringan swadaya masyarakat atau jaringan kerakyatan, mengapa demikian karena untuk biaya pengeluaran perbulannya akan jauh lebih terjangkau daripada dari harga ISP Resmi. Jaringan intenet ini biasa disebut dengan ISP Lokal karena wilayah cakupannya hanya bersifat antar kecamatan atau pedesaan. Dengan adanya internet maka dapat memberikan kemudahan proses komunikasi yakni dengan meniadakan jarak dan waktu yang selama ini dirasakan sebagai faktor penghambat khusunya di desa dan kecamatan yang masih jarang terjangkau kabel telepon. Jaringan Internet menggunakan Antena Wirreless ini dapat memberikan kemudahan dan kenyaman akses internet untuk warga di Pedesaan. Jaringan internet ini menggunakan antena Wirreless sebagai media transmisi data atau penghantar internet, dan Jaringan ini menggunakan mikrotik RB 750 dimana mikrotik disini berfungsi untuk mengatur lalu lintas jaringan.

Kata kunci :Internet, Antena Wireless, mikrotik RB 750, ISP Lokal. 


\section{Pendahuluan}

Permasalahannya sampai saat ini keberadaan ISP masih terkonsentrasi di kota - kota besar saja, sehingga bagi sebagian besar di daerah Desa atau kecamatan masih harus membuat sambungan antar - kota (sambungan langsung jarak jauh / SLJJ). Tetapi untuk dapat menikmati fasilitas pemakaian internet di rumah dengan kecepatan tinggi nampaknya masih mahal karena tarif yang ditawarkan oleh ISP besar atau penyedia jasa layanan internet yang resmi masih cukup mahal, inilah yang menurunkan minat sebagian orang untuk berinternet.

Pada teknologi jaringan Wirreless inilah nantinya menggunakan alat antena Wirreless yang di gunakan untuk mengirim sinyal internet ke sejumlah client, jadi di butuhkan 2 antena yang bertugas sebagai pemancar dan penerima sinyal dari antena server pusat dengan ketinggian yang di sesuaikan sehingga akses dari manapun mampu tercover. Jaringan ini menggunakan Mikrotik OS sebagai server pengatur lalu lintas data, juga manajemen pendistribusian bandwith ke client dalam hal ini menggunakan metode Dial-Up Point-to-Point Protocol over Ethernet (PPPOE). Jaringan Internet Wirreless inilah yang menjadi solusi atau alternatif untuk mengakses Internet bagi rumah dan instansi untuk mengatasi mahal dan langkanya sambungan telepon.

\section{Gambaran Umum Obyek Penelitian}

Pada penelitian ini penulis mengambil obyek penelitian di kecamatan Purwoasri Kabupaten Kediri. Kecamatan purwoasari kabupaten kediri terletak di utara ibukota kabupaten,dengan luas wilayah 42,14 km2 terdiri dari 23 desa. Merupakan kecamatan dengan jumlah desa terbanyak di kabupaten kediri. Semua desa terletak di daerah dataran rendah, beberapa desa terletak di kiri kanan jalan negara kediri kertosono. Batas wilayahnya sebelah barat sungai berantas, sebelah utara kabupaten jombang, sebelah timur kecamatan kunjang dan pelemahan serta sbelah selatan kecamatan Papar.

Dari 23 desa tersebut ada 69 dusun, 147 rukun warga dan 425 rukun tetangga, dengan jumlah perangkat desa sejumlah 218 petugas. Penduduk kecamatan purwosari pada tahun 2011 sejumlah 59.789 jiwa terdiri 29.230 laki-laki dan 30.559 perempun. Jumlah ini menurun 0,33\% di banding tahun 2010, jumlah rumah tangga 14.607 dengan kepadatan penduduk 1.419 jiwa per km2.

Di sektor pendidikan terhadap 99 lembaga pendidikan, baik formal maupun non formal, yang terbanyak adalah TK swasta sejumlah 35 buah. Petugas kesehatan tercatat 66 orang, terbanyak bidan (27 orang). Jumlah pemeluk agama islam sebagai agama mayoritas sejumlah 59.396 jiwa atau 99,94\% dari total penduduk. Pernikahan yang tercatat di KUA sebanyak 559.

Pertanian didominasi oleh tanaman padi dan pawijaya yaitu padi dengan produksi 29.054,20 ton jagung jumlah produksi mencapai 17,795,70 ton untuk data induksi, perdagangan, dan perhubungan realif tidak banyak perubahan di banding tahun lalu. Perolehan PBB kecamatan purwosari sebanyak Rp 1.402,67 juta rupiah. (BPS Kabupaten Kediri, 2011: 5)

\section{Analisis Proses Bisnis}

Proses bisnis adalah suatu kumpulan pekerjaan yang saling terkait untuk menyelesaikan suatu masalah tertentu. Suatu proses bisnis dapat dipecah menjadi beberapa subproses yang masing-masing memiliki atribut sendiri tapi juga berkontribusi untuk mencapai tujuan dari super prosesnya. Analisis proses bisnis umumnya melibatkan pemetaan proses dan subproses didalamnya hingga tingkatan aktivitas atau kegiatan.

Secara Ekonomi sistem yang akan dibangun ini layak untuk diterapkan, karena banyak sekali manfaat positif yang akan diperoleh, selain itu di daerah Purwoasri Kabupaten Kediri banyak desa yang masih kesulitan mendapatkan akses internet. Karakteristik Proses bisnis yang tertera diatas itu akan diuraikan dengan jelas pada proses bisnis kali ini, sehigga akan lebih jelas akan terlihat keuntungan dari pembangunan sistem ini nantinya. 
Dibawah ini akan di uraikan perbedaan antara tarif paket yang dari sistem yang akan di bangun dengan tarif paket speedy saat penelitian ini dilakukan :

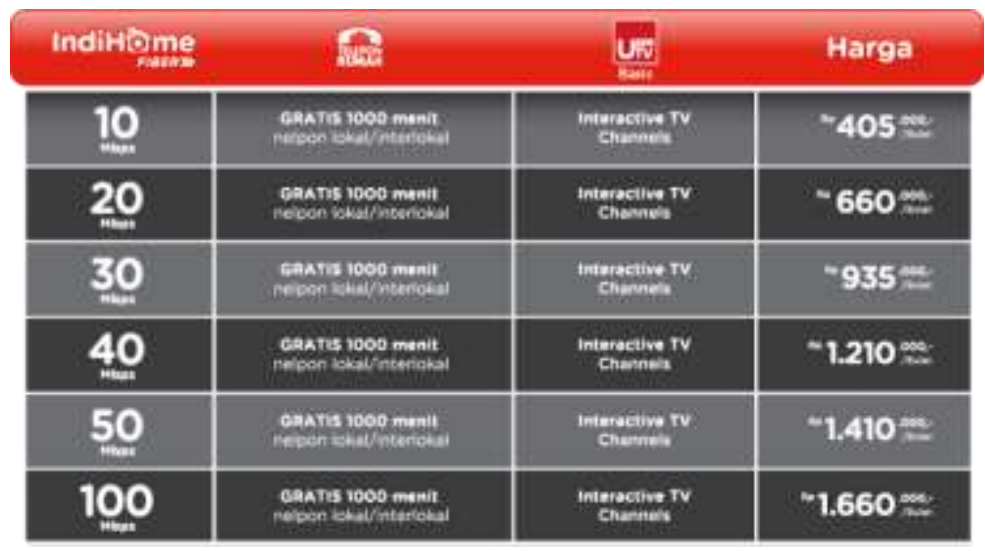

Gambar 1. Tarif Speedy Indihome

Gambar di atas merupakan tarif internet speedy Indihome. Seperti yang kita ketahui Indihome menerapkan batas minimal bandwith untuk pelanggan dengan kecepatan $10 \mathrm{Mbps}$ dengan tarif 400.000 lebih, sedangkan di mayoritas pedesaan dengan tarif sebesar itu akan merasa terbenani dan juga butuh waktu lama untuk memesan Internet Speedy dikarenakan minimnya kabel telepon.

Sedangkan paket yang ditawarkan oleh WiFi dengan Jaringan Wirreless yang akan dibangun ini adalah :

\begin{tabular}{|c|c|}
\hline BANDWITH/SPEED & HARGA \\
\hline 512 kbps & Rp. 70.000, \\
\hline 1 Mbps & Rp. 100.000,- \\
2 Mbps & Rp. 150.000,- \\
3 Mbps & Rp. 220.000,- \\
5 Mbps & Rp. 350.000,- \\
\hline
\end{tabular}

Gambar 2. Paket Internet Wifi Jaringan Wirreless

Kelebihan pada paket yang akan di buat di atas yaitu masyarakat bisa merasakan akses internet dengan biaya yang terjangkau dan sesuai kebutuhan, selain itu proses pemasangannya juga cepat karena menggunakan media Wireeless. Paket ini client dapat menambah banyak PC karena menggunakan IP static sebagai IP Public nya. Kelebihan dari semua paket yang ditawarkan oleh sistem ini adalah tidak adanya kuota yang membatasi, kecepatannya stabil sehingga membuat client tidak merasa dirugikan. Maka dari itu sistem ini layak untuk Dikembangkan di Wilayah Desa Kempleng, Kecamatan Purwoasri dan sekitarnya.

\section{Perancangan}

\subsection{Kebutuhan Perangkat Keras}

Perangkat keras dalam sistem memiliki peranan untuk menjalankan sistem. Perangkat keras masing-masing memiliki fungsi yang berbeda-beda, tetapi mempunyai tujuan yang sama yaitu untuk menjalankan atau menghidupkan sistem. Berikut ini merupakan daftar perangkat keras yang digunakan : 
1) Mikrotik Router

Dalam sistem ini penulis menggunakan Mikrotik RouterBoard sebagai server jaringan. Mikrotik ini berfungsi sebagai pengatur data, lalu lintas jaringan, pembagian bandwith, dan pengontrol client. Dalam sistem ini penulis menggunakan Mikrotik Tipe RB750UP dengan spesifikasi sebagai berikut :

$\begin{array}{llll}\checkmark & \text { Architecture } & : & \text { MIPS-BE } \\ \checkmark & \text { CPU } & : & \text { QCA9531 650MHz } \\ \checkmark & \text { Main Storage/NAND } & : & 16 \mathrm{MB} \\ \checkmark & \text { RAM } & : & 64 \mathrm{MB} \\ \checkmark & \text { POE Input } & : & 10-28 \mathrm{~V} \\ \checkmark & \text { LAN Port } & : & 5 \\ \checkmark & \text { RouterOS License } & : & \text { Level } 4\end{array}$

2) Antena Pemancar

Dalam perancangan sistem ini penulis menggunakan antena dari merk Ubiquty dengan type Nanostation M5 16dbi Airmax untuk menghantarkan internet ke client, antena tersebut memiliki frekuensi $5 \mathrm{Ghz}$ jadi hanya bisa di tangkap dengan antena frekuensi 5 Ghz. Berikut spesifikasinya :

$\begin{array}{llll}\checkmark & \text { Frekuensi Sinyal } & : & 5,4-5.825 \mathrm{GHz} \\ \checkmark & \text { DHCP } & : & \text { yes } \\ \checkmark & \text { Procesor } & : & \text { MIPS 24KC, } 400 \mathrm{MHz} \\ \checkmark & \text { RAM } & : & 32 \mathrm{MB} \\ \checkmark & \text { NAND } & : & 8 \mathrm{MB} \\ \checkmark & \text { Transmission speed } & : & 300 \mathrm{Mbps} \\ \checkmark & \text { Standards } & : & 802.11 \mathrm{a} / \mathrm{n} \\ \checkmark & \text { Chipset } & : & \text { Atheros } \\ \checkmark & \text { Max.output power } & : & 27 \mathrm{dBm}\end{array}$

3) Acces Point atau Wirreles Router

Dalam sistem ini Acces Point inilah yang di gunakan untuk mengakses internet oleh komputer client dan sebagainya yang mempunyai koneksi Wifi.

4) Kabel Jaringan

Dalam sistem ini kabel jaringan berfungsi untuk menghantarkan daya atau bandwith internet dari perangkat 1 ke perangkat yang lain, kabel yang digunakan adalah kabel Unsielded Twisted Pair (UTP) dan Shielded Twisted Pair (STP).

\subsection{Kebutuhan Perangkat Lunak}

Perangkat lunak yang dibutuhkan dalam sistem ini adalah :

1) Sebuah Sistem operasi baik Microsoft Windows, Linux dan lain-lain.

2) Winbox yaitu aplikasi yang digunakan untuk konfigurasi Miktorik Server

\subsection{Spesifikasi Tiang Pemancar atau Tower}

Dalam perancangan sistem ini, di karenakan akan menggunakan media wirreless maka di perlukan sebuah Tiang atau Tower sebagai tempat antena wirreless tersebut. Berikut spesifikasi tower yang akan di dirikan : 


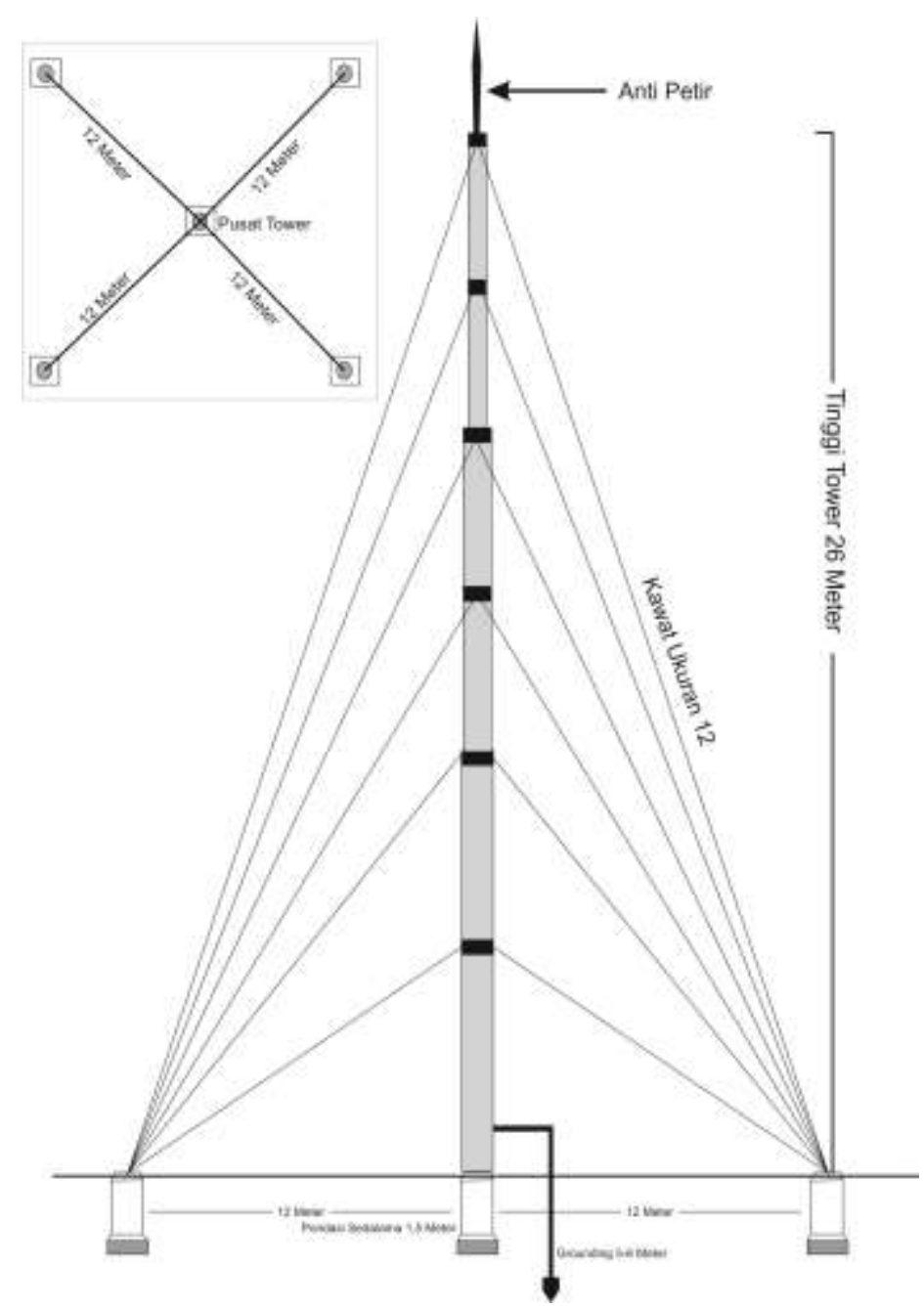

Gambar 3. Rancang Bangun Tower

Penjelasan gambar tersebut adalah : tower yang akan di buat memiliki ketinggian 26 meter dengan menggunakan Pipa Besi tipe BS A sebagai komposisi Tiang utama. Pipa Besi yang digunakan sebanyak 5 buah pipa Besi dengan Ukuran 3Dim sebanyak 1 buah, 2,5Dim 2 buah, 2Dim 1 buah dam 1,5Dim 1 buah. Luas tanah yang dibutuhkan adalah 12 x 12 meter persegi dengan 4 bentang kawat yang akan menyangga pipa tersebut dengan pondasi sedalam 1,5 Meter.

\subsection{Topologi Jaringan}

Dalam perancangan akan dibuat suatu Penggunaan manajemen Jaringan Wirreless, yaitu melalui Router Mikrotik sedangkan perangkat Antena, Access Point dan Switch Hub merupakan pengantar access terhadap client. Dalam jaringan ini di media Wirreless. Pada bagian layanan Router Mikrotik paket yang digunakan NAT, IP, PPPoE. Sedangkan IP address terhadap user di bagi menjadi 2 network Addres yang berbeda yaitu IP untuk DHCP dan IP Statik untuk WAN PPPoE. Penjelasannya sebagai berikut, IP yang di setting DHCP, IP tersebut digunakan untuk jaringan umum dan diaplikasikan ke radio AP atau antena pemancar dan penerima, di antena tersebut nantinya akan di mode static IP. Sedangkan IP address Statik untuk WAN PPPoE di aplikasikan ke Acces Point atau Wireless Router untuk dijadikan sebagai layanan IP Publik. Berikut skema topologi jaringan yang akan diterapkan : 


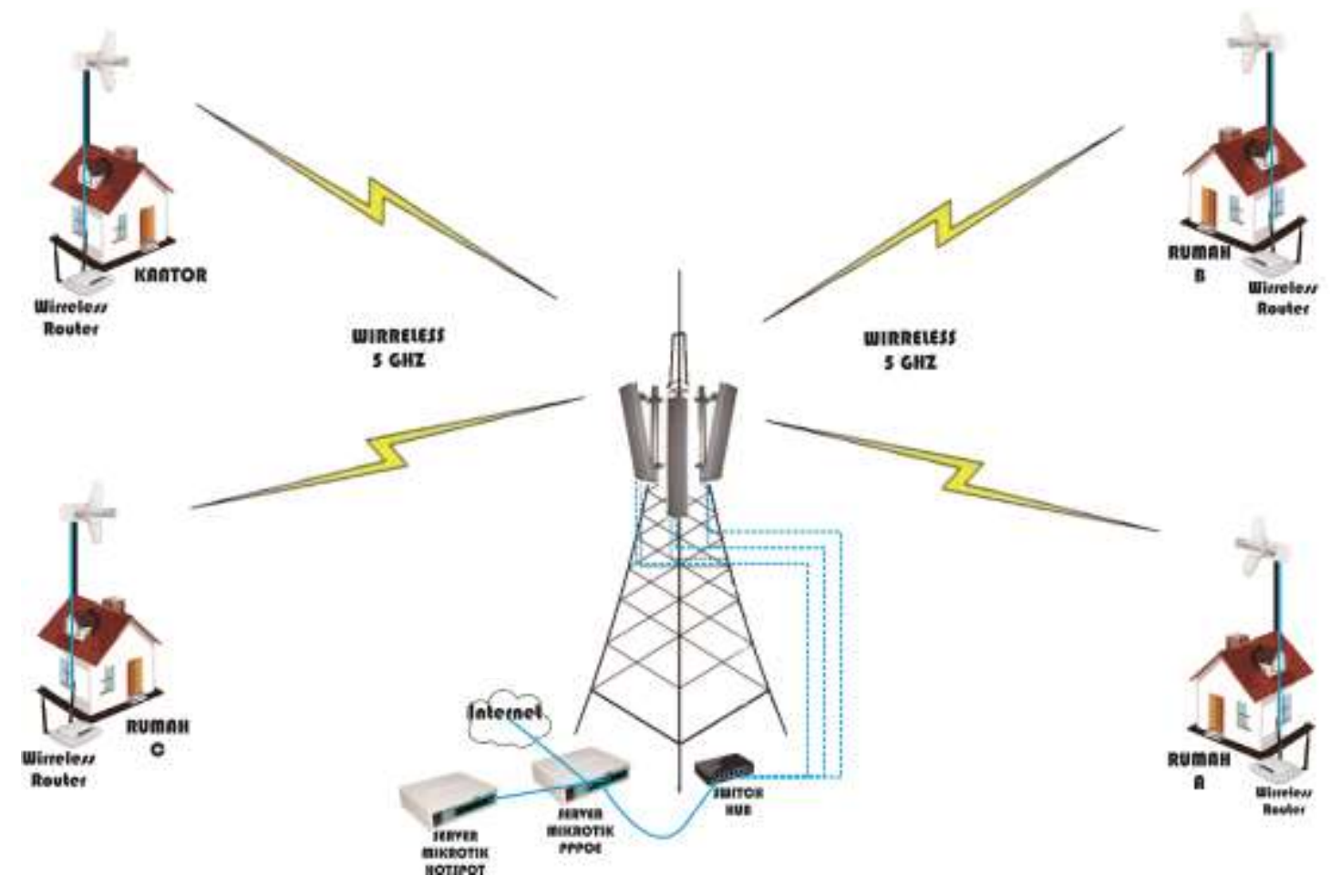

Gambar 4. Skema Jaringan yang akan diterapkan

Pada skema di atas jaringan Internet Service Provider (ISP) pusat juga dari Jaringan Wirreless bukan dari kabel telepon karena minimnya kabel telepon di daerah pedesaan, jaringan tersebut di sambungkan di ethernet port 5 sebagai jaringan utama. Bedasarkan penjelasan di atas bahwa jaringan ini di bagi menjadi 2 network sebagai IP local, berikut perinciannya :

1. Yang pertama, IP Untuk DHCP Server. IP Localnya adalah 192.168.50.1, Subnet Masknya adalah 255.255.255.0 dengan Range IP 192.168.50.2-192.168.50.254. IP inilah yang di aplikasikan ke Antena Pemancar dan Penerima.

2. Yang kedua, IP untuk koneksi WAN PPPoE. Pada kali ini hanya menggunakan IP Local karena IP akan di berikan secara manual secara berurutan setiap client, IP inilah yang akan menjadi IP Statik dari Access Point atau Wirreless Router. IP Localnya adalah 192.168.49.1 dengan subnet Mask 255.255.255.0

Kedua IP di atas akan di olah di server mikrotik di Port 1 sampai 4 dengan menggunakan jaringan Bridge yaitu menggabungkan beberapa port menjadi satu jaringan, supaya tidak terlalu banyak memerlukan konfigurasi IP di setiap Port. Dari Port 1 sampai 4 tadi akan di sambungkan ke Switch Hub untuk membagi ke jaringan local termasuk antena Wirreless juga di tancapkan ke Switch Hub. Dari Antena akan di pancarkan dengan sinyal 5 Ghz kemudian di tangkap menggunakan antena penerima yang juga frekuensi 5Ghz, setelah dari antena penerima akan di teruskan melalui kabel ke Access Point atau Wirreless Router yang di tancapkan ke Port WAN dari perangkat Wirreless Router, dan setelah terkoneksi maka jaringan internet dapat di akses melalui perangkat tersebut.

\section{Implementasi dan Pembahasan}

ISSN Print $\quad: 1979-7141$ 
Sebelum implementasi, penulis akan membahas kualitas koneksi antar client dengan menunjukkan data di bawah ini. Karena koneksi dengan jaringan wirreless maka koneksi client ke server sangat berpengaruh terhadap kualitas sebuah jaringan. Tabel berikut ini menyajikan hasil pengujian kualitas koneksi antenna wireless.

Tabel 1. Hasil Pengujian Kualitas Koneksi

\begin{tabular}{|l|l|l|l|c|c|}
\hline \multicolumn{1}{|c|}{$\begin{array}{c}\text { Tipe } \\
\text { Antena }\end{array}$} & Jarak & Ketinggian & \multicolumn{1}{|c|}{ Halangan } & $\begin{array}{c}\text { Kualitas } \\
\text { ccq }\end{array}$ & $\begin{array}{c}\text { Kapasitas } \\
\text { Bandwith }\end{array}$ \\
\hline $\begin{array}{l}\text { AirGrid M5 } \\
\text { HP }\end{array}$ & $3,5 \mathrm{Km}$ & 16 Meter & $\begin{array}{l}\text { Beberapa Pohon } \\
\text { tinggi 18 Meter }\end{array}$ & $83,4 \%$ & $22,91 \mathrm{Mbps}$ \\
\hline $\begin{array}{l}\text { AirGrid M5 } \\
\text { HP }\end{array}$ & $3,5 \mathrm{Km}$ & $16 \mathrm{Meter}$ & Sedikit Pohon & $87,9 \%$ & $36,11 \mathrm{Mbps}$ \\
\hline $\begin{array}{l}\text { PowerBeam } \\
\text { M5HP 25dbi }\end{array}$ & $1,5 \mathrm{Km}$ & $12 \mathrm{Meter}$ & $\begin{array}{l}\text { Beberapa Pohon } \\
\text { Tinggi 15 Meter }\end{array}$ & $94,5 \%$ & $87,69 \mathrm{Mbps}$ \\
\hline $\begin{array}{l}\text { PowerBeam } \\
\text { M5HP 25dbi }\end{array}$ & $2,9 \mathrm{Km}$ & 12 Meter & $\begin{array}{l}\text { Beberapa Pohon } \\
\text { Tinggi 15 Meter }\end{array}$ & $97,1 \%$ & $33,5 \mathrm{Mbps}$ \\
\hline $\begin{array}{l}\text { LiteBeam } \\
\text { M5 23dbi }\end{array}$ & $1,5 \mathrm{Km}$ & 12 Meter & $\begin{array}{l}\text { Beberapa Pohon } \\
\text { Tinggi 14 Meter }\end{array}$ & $98,2 \%$ & $41,00 \mathrm{Mbps}$ \\
\hline
\end{tabular}

Berdasarkan hasil pengujian kualitas koneksi dapat dilakukan langkah selanjutnya yaitu Pembuatan Username dan IP Client di Mikrotik OS. Gambar di bawah ini merupakan proses pembuatan username dan IP Adrress client yang berada Mikrotik Server di menu PPP lalu sub menu secret, Username inilah nantinya yang akan digunakan untuk Dial-Out Koneksi Internet di Wirreless Router

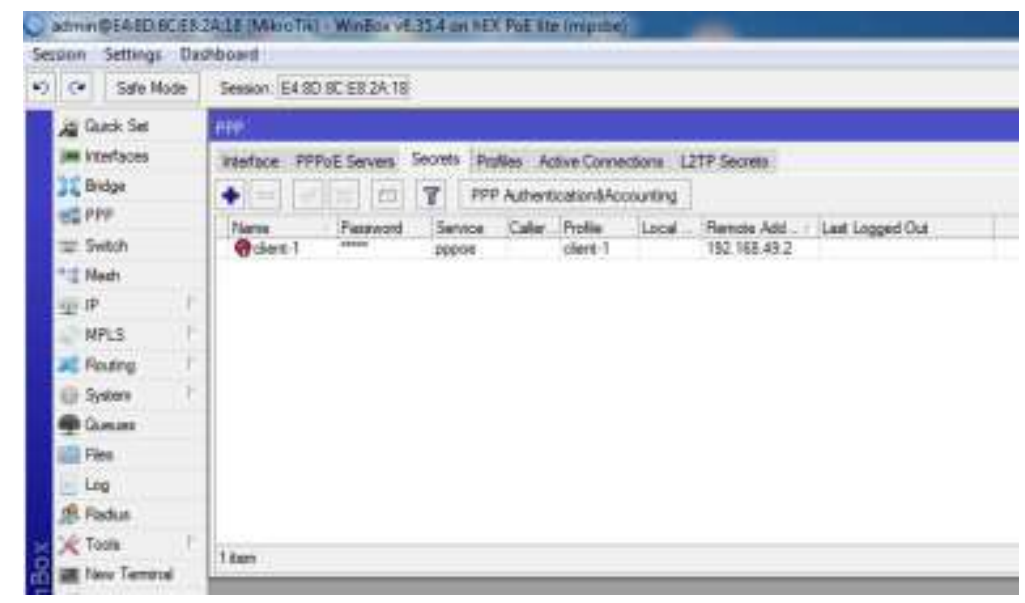

Gambar 5 : Pembuatan Username dan IP Client di Mikrotik

Dalam menjalankan sebagai provider internet tentu saja ada kisaran bandwith yang akan di minta oleh sebuah client atau pelanggan, penulis menggunakan menu Queues lalu di sub menu Simple Queues sebagai pengatur bandwith Client, seperti di gambar 3 
Dalam Sistem ini yang menentukan kualitas jaringan adalah koneksi antara antena Wirreless, penulis akan menjelakan lewat gambar di bawah ini

Untuk sebagai pemancar penulis menggunakan antena merk Ubiquity Nanostation M5 16dbi frekuensi 5Ghz, karena kualitas ubiquity yang dapat membawa bandwith yang besar dan real, antena tersebut memiliki daya pancar 70 derajat sehingga daya pancar akan lebih fokus ke client dan meminimalisir gangguan. Berikut tampilan terlihat pada gambar 4.

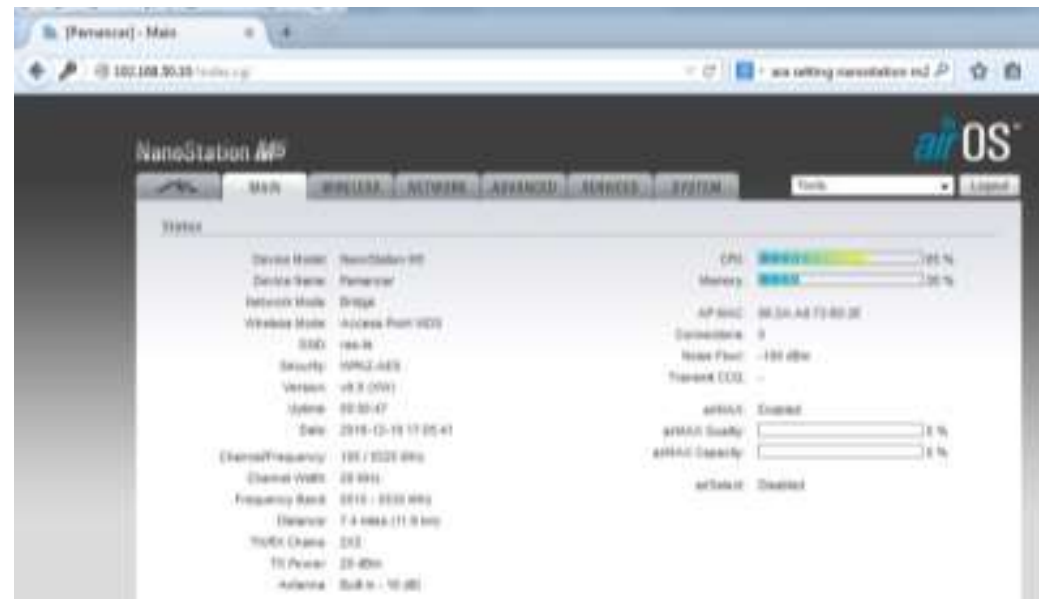

Gambar 7. Antena Pemancar

Sedangkan pada antena client penulis menggunakan Ubiquity Airgrid M5 23dbi dengan frekuensi 5Ghz. Pada antena client yang sudah terkoneksi tertera informasi antena tentang kualitas koneksi jaringan yang terdapat di gambar 5. Penulis akan menjelaskan tentang kualitas koneksi tersebut beserta tes kapasitas bandwitdh. 


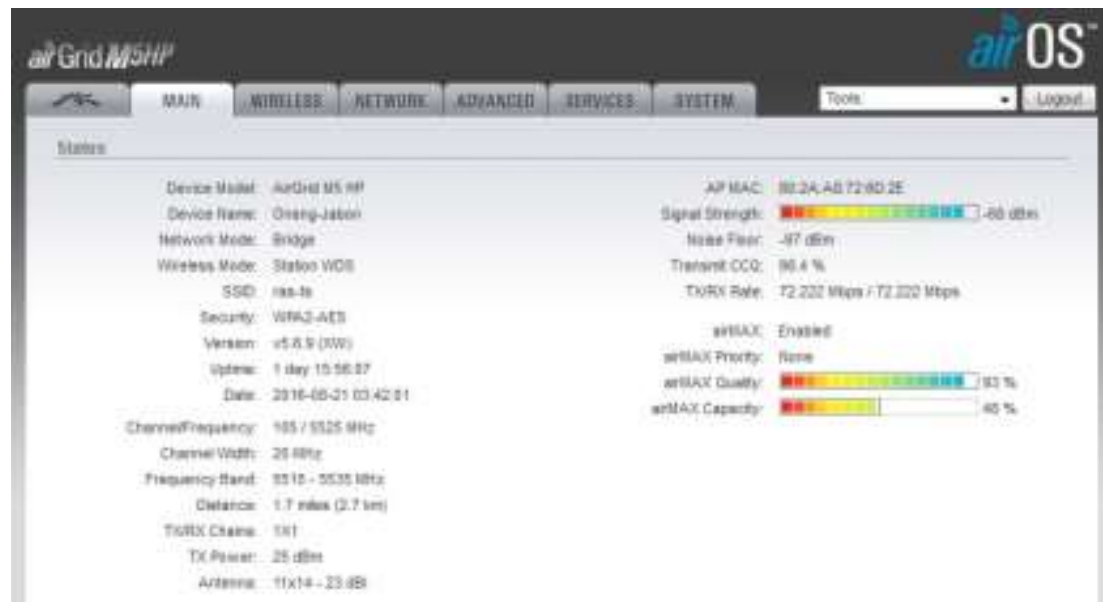

Gambar 8. Antena Client

Pada antena client terdapat 4 kategori yang menjadi kunci kualitas jaringan, Pada gambar 5 terlihat distance atau jarak $2,7 \mathrm{~km}$ yang artinya jarak udara antena client ke server.

Yang pertama Signal strenght yang artinya kekuatan sinyal yang diterima radio client, angka minusnya makin dekat ke 0 semakin kuat signalnya. Yang kedua transmit ccq yang berarti kualitas koneksi jaringan dalam persen pada gambar tersebut menunjjukan $98 \%$, semakin besar persennya semakin bagus link jaringan. Yang ketiga airmax quality yang artinya kualitas request data internet. Yang ke empat adalah airmax capacity yang berarti kapasitas bandwith yang dapat dimuat dalam antena tersebut, tiap persen dapat memuat 1 Mbps dan gambar menunjukkan $48 \%$.

Jadi dalam jarak udara 2,7 $\mathrm{Km}$ tanpa halangan antena tersebut dapat memuat bandwith rata-rata 40 Mbps dan menunjukkan kualitas koneksi jaringan yang stabil. Pada gambar 6 dilakukan speedtest antena client yang menujukkan total kapasitas bandwith yang dapat di muat pada antena client tersebut.

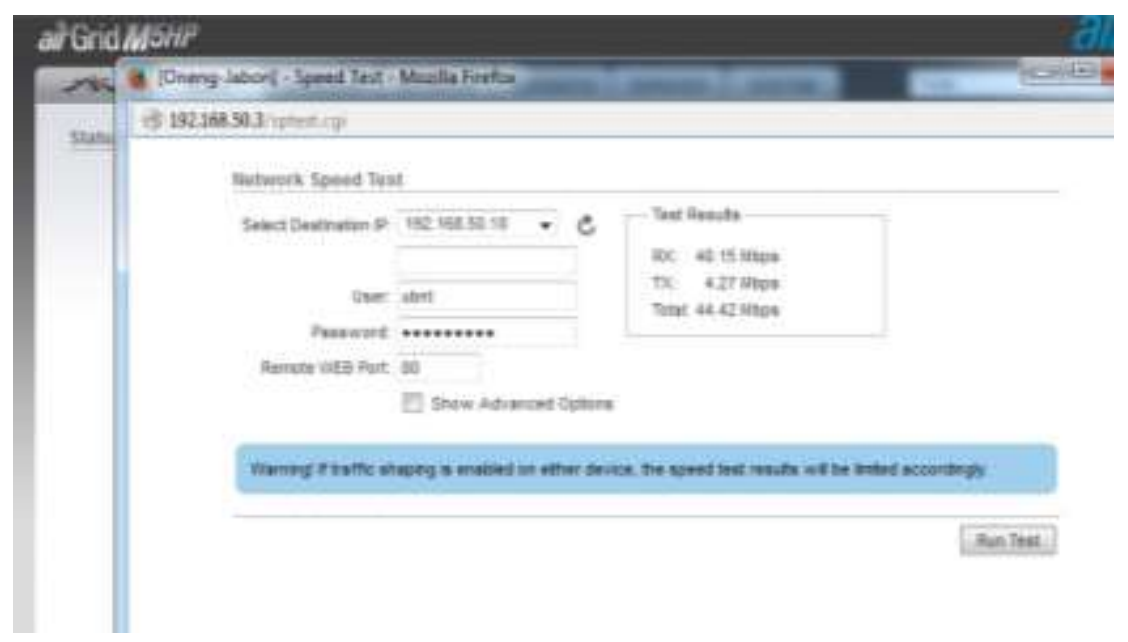

Gambar 9. Speedtest Antena Client

Agar Wirreless router dapat terkoneksi internet dengan mikrotik maka dilakukanlah dial-out pada Access point Wirreless router pada Menu WAN seperti gambar di bawah ini :

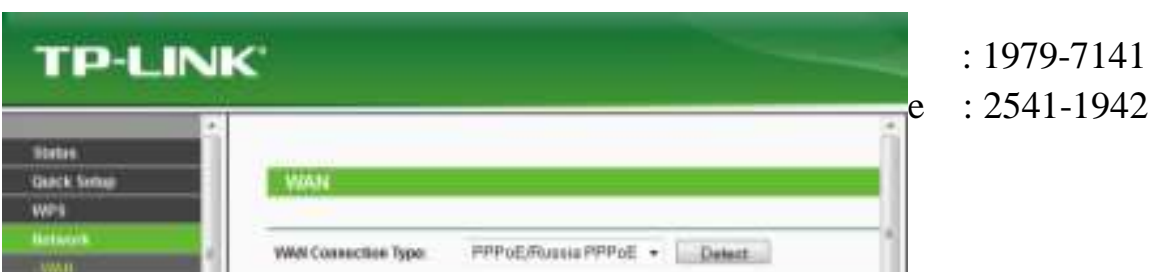


Sedangkan untuk memantau aktifitas client pada server mikrotik, untuk mengetahui aktif tidak nya client maka dilihat di Menu PPP lalu sub menu Interface, seperti pada gambar 8 .

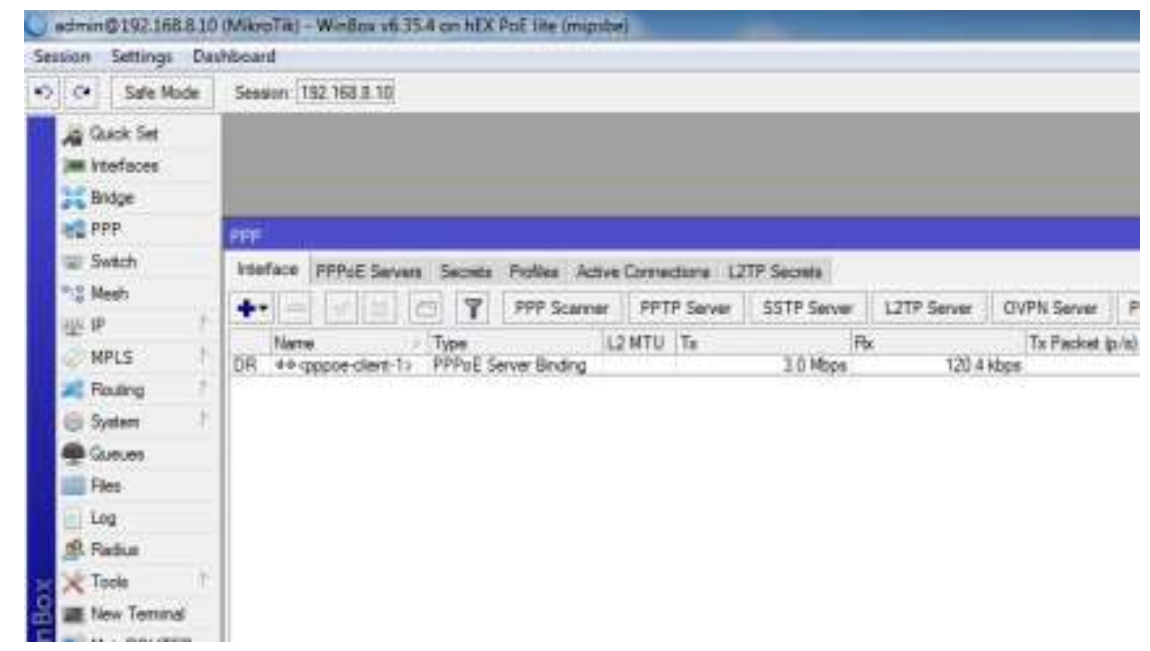

Gambar 11. Aktifitas Client di server mikrotik

\section{Kesimpulan}

Dari pembahasan yang telah diuraikan diatas maka dapat diambil kesimpulan sebagai berikut yaitu, dengan adanya Jaringan Internet Wirreless atau ISP Lokal ini mampu menyelesaikan permasalahan-permasalahan di daerah pedesaan yang juga membutuhkan akses internet karena langkanya kabel telepon dari ISP resmi sehingga lembaga, atau masyarakat yang ada di pedesaan dapat merasakan Internet cepat, stabil dan harga terjangkau. Selain itu Sistem ini karena menggunakan Jaringan Antena Wirreless sebagai media penghantar internet, sehingga di akses darimana saja dapat tercapai dengan kondisi yang disesuaikan. Dan kehandalan dari antena Wirreless yang memungkinkan client mengakses hingga kecepatan 10 mbps lebih menjadikan sistem ini layak dikembangkan di daerah pedesaan. 


\section{DAFTAR PUSTAKA}

BPS Kabupaten Kediri. 2011. Kecamatan Purwoasri dalam Angka: Anggraini. Kediri

Bin Ladjamudin Al Bahra. 2005. Analisis dan Desain Sistem Informasi. Graha Ilmu : Tanggerang. Hartono, Rudi. 2010. Wireless Network. ANDI. Yogyakarta

Herlambang, Moch. Linto dan Catur L., azis. 2008. Panduan Lengkap Menguasai Router Masa Depan Menggunakan Mikrotik RouterOS : ANDI Yogyakarta

Jogiyanto, H.M. 2001. Analisa dan Desain Sistem Informasi Edisi Kedua. andi Offset : Yogyakarta.

Nugroho, Kukuh. 2016. Router Cisco \& Mikrotik: Informatika. Bandung

Kardian, Aqwam Rosadi. 2009. Pengelolaan Bandwith Menggunakan "xxx" Bandwith Management pada ISP WAN : Informatika. Bandung

Sadiman, 2006. Teknologi Informasi dan Komunikasi : Erlangga. Banyuasin.

Sofana, Iwan. 2008. Membangun Jaringan Komputer Membuat Jaringan Komputer (Wire \& Wireless) untuk pengguna windows dan Linux: Informatika. Bandung

Syafrizal, Melwin. 2007. Pengantar Jaringan Komputer : ANDI.Yogyakarta

Stallings, William. 2007. Komunikasi \& Jaringan Nirkabel (Edisi Kedua): Erlangga. Jakarta

Purbo, Onno W. 2001. TCP/IP Standar, Desain dan Implementasi : PT. Elex Media Komputindo. Jakarta 